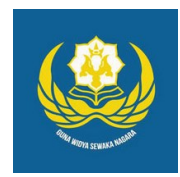

Jurnal Analogi Hukum

Journal Homepage: https://ejournal.warmadewa.ac.id/index.php/analogihukum

\title{
Perlindungan Hukum Terhadap Tenaga Kerja Indonesia di Luar Negeri
}

\author{
Ni Kadek Sintia Dewi*, Desak Gde Dwi Arini dan Luh Putu Suryani \\ Universitas Warmadewa, Denpasar-Bali, Indonesia \\ *sintiadewi@gmail.com
}

\begin{abstract}
How To Cite:
Dewi, N, K, S., Arini, D, G, D., Suryani, L, P. (2021). Perlindungan Hukum Terhadap Tenaga Kerja Indonesia di Luar Negeri. Jurnal Analogi Hukum. 3 (1). 37-41. Doi: https://doi.org/10.22225/ah.3.1.3039.37-41
\end{abstract}

\begin{abstract}
Indonesian Workers, hereinafter referred to as TKI, are every Indonesian citizen who meets the requirements to work abroad in employment relations for a certain period of time by receiving wages. In the case of the placement of overseas Indonesian Workers held by Indonesian Manpower Services Companies must be in accordance with the terms and procedures specified in the legislation. After the terms and procedures are fulfilled, a work agreement is made concerning legal protection for the rights of Indonesian Workers. With the employment agreement, Indonesian Workers who work abroad will receive legal protection at pre-placement, placement and after-placement. The problem in this study is regarding the regulation of employment agreements and placement of Indonesian workers abroad and forms of legal protection for Indonesian workers abroad. The research method used in the discussion of this paper, the authors use the main approach, namely the Statute Approach and the Conceptual Approach as supporting the legislative approach, the source of the legal material for writing is obtained from the literature with the type of legal material in the form of material primary law and secondary legal material. The results of this study found that the weak protection of Indonesian workers is due to two main factors, namely the implementation factor of the protection law issued by the government does not work as it should, and a weak coordination factor between related stakeholders.
\end{abstract}

Keywords: Indonesian Workers; Legal Protection; Overseas

\begin{abstract}
Abstrak - Tenaga Kerja Indonesia yang selanjutnya disebut dengan TKI adalah setiap warga negara Indonesia yang memenuhi syarat untuk bekerja di luar negeri dalam hubungan kerja untuk jangka waktu tertentu dengan menerima upah. Dalam hal Penempatan Tenaga Kerja Indonesia keluar negeri yang diselenggarakan oleh Perusahaan Jasa Tenaga Kerja Indonesia harus sesuai dengan syarat dan prosedur yang ditentukan dalam peraturan perundang-undangan. Setelah syarat dan prosedur terpenuhi, maka dibuat perjanjian kerja yang menyangkut perlindungan hukum terhadap hak-hak Tenaga Kerja Indonesia. Dengan adanya perjanjian kerja, maka Tenaga Kerja Indonesia yang bekerja di luar negeri akan memperoleh perlindungan hukum pada saat pra penempatan, masa penempatan dan purna penempatan. Permasalahan dalam penelitian ini adalah mengenai pengaturan perjanjian kerja dan penempatan tenaga kerja Indonesia di luar negeri dan bentuk perlindungan hukum terhadap tenaga kerja Indonesia di luar negeri. Metode penelitian yang digunakan dalam pembahasan penulisan ini, penulis menggunakan pendekatan utama yaitu pendekatan perundang-undangan (The Statute Approach) dan pendekatan Konseptual (conceptual Approach) sebagai penunjang pendekatan perundangundangan, sumber bahan hukum penulisan diperoleh dari kepustakaan dengan jenis bahan hukum berupa bahan hukum primer dan bahan hukum sekunder. Hasil penelitian ini menemukan bahwa Lemahnya perlindungan tenaga kerja Indonesia ini dikarenakan dua faktor utama yaitu faktor implementasi dari UndangUndang perlindungan yang di keluarkan oleh pemerintah tidak berjalan dengan sebagaimana mestinya, dan faktor kordinasi yang kurang antar stakeholder terkait.
\end{abstract}

Kata Kunci: Tenaga Kerja Indonesia; Perlindungan Hukum; Luar Negeri

Jurnal Analogi Hukum, Volume 3, Nomor 1, 2021. CC-BY-SA 4.o License 


\section{Pendahuluan}

Jawa dan Madura termasuk pulau padat penduduk, terdapat banyak sumber daya manusia berpotensi sebagi sumber tenaga kerja yang ahli dibidangnya (Supomo, 1999). Memperoleh pekerjaan merupakan hak bagi setiap orang untuk mengembangkan diri seperti dituangkan dalam Konstitusi Negara Republik Indonesia bahwa setiap warga Negara berhak atas pekerjaan dan penghidupan yang layak (Fuqoha, 2018). Target pemerintah dalam menyediakan lapangan kerja yang banyak untuk bisa mengatasi permasalahan ekonomi di indonesia selama ini belum bisa tercapai untuk direalisasikan. Tingginya jumlah angka pengangguran yang menyebabkan negara tidak maju merupakan faktor dari sedikitnya lapangan kerja. Salah satu penyebab dari tingginya angka pengangguran di Indonesia yaitu tidak terlepas dari pendidikan dan pengetahuan yang rendah. Laju tingkat pengangguran berjalan beriringan dengan tingkat kemiskinan yang ada saat ini, apabila terdapat banyak pengangguran maka laju kemiskinan akan terus meningkat.

Indonesia dengan jumlah penduduk kurang lebih berjumlah 230 juta jiwa dan kurangnya lapangan kerja mengakibatkan tidak sedikit rakyat Indonesia mencari nafkah ke negeri seberang dengan cara menjadi seorang tenaga kerja Indonesia.

Jalan menjadi seorang TKI tidaklah semudah yang dibayangkan. Walaupun budaya dan bahasa yang berbeda tidak menyurutkan anime masyarakat untuk takut menjadi seorang TKI di luar negeri. Ini merupakan solusi untuk mengatasi kemiskinan yang terjadi pada diri seseorang agar bisa mempertahankan hidupnya walaupun harus meninggalkan keluarga tercinta dalam waktu yang lumayan lama.

Upah besar yang ditawarkan meruakan faktor utama penyebab seorang menjadi TKI (Supomo, 1999). Namun permasalahan banyak menghampiri TKI selama bekerja di luar negeri. Mulai dari permasalahan pelanggaran hak asasi manusia sampai dengan masalah perdagangan manusia yang sering menghantui TKI. Pekerja juga sering mendapatkan masalah akibat dari dirinya sendiri karena menjadi seorang yang ilegal di negara orang.

Sangat memprihatikan dengan maraknya kekerasan yang terjadi terhadap TKI selama ini. Malaysia dan Saudi Arabia negara yang tercatat dimana TKI sering mendapat pelanggaran HAM yang dilakukan sang majikan.
Sumiati merupakan salah satu contoh korban kekerasan yang dilakukan di saudi arabia. Setelah dilakukan penyelidikan di negara tempatnya bekerja, ditemukan beberapa luka dari luka sedang hingga sangat parah pada tubuhnya. Kakinya pun di vonis dokter mengalami kelumpuhan akibat dari penyiksaan diberitakan pada media masa tempatnya bekerja. Kejadian seperti ini menimbulkan pemikiran bahwa pemerintah Indonesia kurang melindungi wargaya yang pencari penghidupan di negara oarang lain.

Perlindungan terhadap tenaga kerja Indonesia yang bekerja di luar negeri merupakan bagian dari kewajiban negara untuk memenuhi hak-hak konstitusional sebagai warga negara. Undang-Undang Nomor 39 Tahun 2004 Tentang Penempatan dan Perlindungan Tenaga Kerja Indonesia merupakan bagian integral dari sistem yang dibangun berdasarkan amanat Pasal $28 \mathrm{D}$ ayat 3 , dimana setiap warga negera berhak untu mendapatkan pekerjaan yang layak (Muin, 2015). Dikeluarkannya Undang-Undang No. 39 tahun 2004 tentang penempatan dan perlindungan tenaga kerja indonesia di luar negeri diharapkan pemerintah bisa menekan angka korban kekerasan terhadap tenaga kerja Indonesia di luar negeri, untuk mencegah terjadinya TKI ilegal. Dalam undang-undang ini mengatur mengenai perjanjian kerja dan penempatan untuk para TKI.

Berdasarkan dari uraian latar belakang diatas adapun rumusan masalah yang akan penulis bahas, yaitu:

Bagaimana pengaturan perjanjian penempatan Tenaga Kerja Indonesia di luar negeri?

Bagaimana bentuk perlindungan hukum terhadap Tenaga Kerja Indonesia di luar negeri?

Setiap penelitian memiliki tujuan, adapun tujuan dari penelitian ini, yaitu:

Untuk mengetahui pengaturan perjanjian penempatan Tenaga Kerja Indonesia di luar negeri.

Untuk mengetahui bentuk perlindungan hukum terhadap Tenaga Kerja Indonesia di luar negeri.

\section{Metode}

Dalam penelitian ini penulis menerapkan metode penelitian hukum normatif yakni melakukan upaya melalui pengkajian terhadap bahan hukum dari literatur. Dalam penelitia ini 
penulis menggunakan pendekatan masalah yaitu pendekatan secara peundang-undangan dan pendekatan secara konseptual. Pendekatan perundang-undangan ialah suatu pendekatan dimana suatu peraturan perundangan-undangan dikaji lebih dalam dan khusus peraturan perundang-undangan tersebut juga berhubungan dengan permasalahan yang ada. Sedangkan pendekatan konseptual merupakan suatu pendekatan yang di dalam ilmu hukum ada dan bekembang pemikiran dan doktrin para sarjana.

Adapun sumber bahan hukum yang digunakan penulis akan digunakan yaitu bersumber dari penelitian dan kepustakaan, berupa:

Bahan hukum primer bersifat mengikat contoh peraturan perundang-undangan yang berhubungan dengan apa yang akan dibahas dalam permasalahan, misalnya: UndangUndang Dasar Negara Republik Indonesia Tahun 1945; Kitab Undang-Undang Hukum Perdata; UU Nomor 13 Tahun 2003 Tentang Ketenagakerjaan; UU Nomor 39 Tahun 2004 tentang Penempatan dan Perlindungan Tenaga Kerja Indonesia di Luar Negeri; Peraturan Menteri Ketenagakerjaan Republik Indonesia Nomor 22 Tahun 2014 Tentang Pelaksanaan Penempatan Dan Perlindungan Tenaga Kerja Indonesia Di Luar Negeri.

2. Bahan hukum sekunder yaitu bersifat menegaskan bahan hukum utama yang digunakan, seperti misalnya buku literatur, pendapat para sarjana sebagai referensi memperbanyak pengetahuan penulis akan bidang penulisan.

3. Bahan hukum tersier yaitu bahan yang memberikan petunjuk maupun penjelasan terhadap bahan hukum primer dan sekunder, contohnya kamus.

Teknik yang digunakan untuk penghimpunan bahan hukum yang dibutuhkan dalam pengkajian ini diperoleh dengan cara melakukan pendalaman kepustakaan berbagai sumber literatur. Melalui upaya menelusuri, meringkas, mencatat lalu mendalami dengan mendalami buku-buku ilmiah yang mengandung gagasan para pakar dan ahli. Bahan hukum yang sudah dapat dirangkai tersebut kemudian akan dibuat pengeditan terhadap bahan hukum, keterangan bahan hukum yang signifikan dan analis secara terstruktur.

\section{Hasil Penelitian Dan Pembahasan}

\section{Pengaturan Perjanjian Kerja Dan}

\section{Penempatan Terhadap Indonesia Di Luar Negeri \\ Tenaga Kerja}

Suatu perjanjian kerja timbul akibat dari adanya hubungan kerja oleh majikan dan buruh. Pasal 1 angka 15 uu no. 13 tahun 2003 tentang ketenagakerjaan menentukan bahwa: perintah, pekerjaan dan upah merupakan unsur dari perjanjian kerja yang timbul karena suatu hubungan kerja. Apabila sudah sah dan mengikat kedua belah pihak dalam perjanjian tersbut yang mencatumkan pekerjaan dan upah yang telah di sepakati merupakan contoh perjanjian kerja konsensual (Subekti, 1994).

Pemerintah bertujuan dengan adanya penempatan tenaga kerja Indonesia ke luar negeri bisa mensejahterakan warganya akibat dari kurangnya lapangan kerja di indonesia. Mengingat pentingnya sebuah pekerjaan, uu dasar negara republik Indonesia tahun 1945 menentukan bahwa: setiap rakyat Indonesia berhak atas pengidupan yang layak bagi dirinya.

Pemerintah akhirnya mengeluarkan uu no. 39 tahun 2004 untuk melindungi segenap warga negara Indonesia yang bekerja di luar negeri. Undang-undang ini sudah mencakup mengenai perjanjian penempatan yang dilakukan oleh calon TKI yang berikan mengenai hak dan kewajiban para pihak yang ada di dalamnya.

Pasal 8 uu no. 39 tahun 2004 menentukan setiap calon TKI berhak atas pekerjan di luar negeri; bebas menganut agama dan keyakinan; menerima upah yang sewajarnya; mendapatkan jaminan perlindungan hukum; dan mendapat hak dan pelakuan sama dengan tenaga asing lainnya. Dari sini bisa dilihat apa saja yang menjadi kewajiban seorang majikan.

Kewajiban calon TKI juga ditentukan dalam pasal 9 uu no. 39 tahun 2004 antara lain harus mematuhi segala peraturan yang ada di dalam maupun luar negeri tempat tujuan bekerja; membayar jasa penyedia layanan TKI sesuai dengan perjanjian yang dibuat sebelumnya; dan berprilaku baik selama berada di luar negeri.

Adapun pihak-pihak yang terkait dalam penempatan TKI ini meliputi; calon TKI itu sendiri, penyedia layanan pemberangkatan TKI; mitra usaha yang berbadan hukum; pengguna jasa TKI.

Sebuah lembaga non Dapartemen juga dibentuk oleh pemerintah guna memperlancar penempatan TKI ke luar negeri. BNP2TKI merupakan kepanjangan dar Badan Nasioal Penempatan dan Perlindungan Tenaga Kerja 
Indonesia didirikan untuk melaksanakan tugas pengayoman dari hal pengurusan dokumen hingga pemeberangkatan TKI.

Pasal 31 uu no.39 tahun 2004 menentukan tahapan yang yang dilewati untuk menjadi seorang TKI yang legal, ialah dengan pengurusan surat izin pengerhana; pemilihan dan penyaringan; pendidikan dan pelatihan kerja; pemeriksaan kesehatan dan psikologi; pengursan dokumen; uji kompetensi; pemebekalan akhir pemberangkatan; dan akhirnya di berangkatkan ke negara tujuan.

\section{Bentuk Perlindungan Hukum Terhadap Tenaga Kerja Indonesia Di Luar Negeri}

Mewujudkan kegiatan pengayoman oleh penguasa diberikan kepada setiap hak asasi manusia untuk memberikan rasa aman sebagai bentuk wujud perlindungan hukum akibat kerugian yang ditimbulkan akibat suatu kejahatan, dari ancaman yang mengganggu pikiran maupun fisik seseorang (Raharjo, 2000).

Perlindungan TKI dilakukan pemerintah guna menekan angka kekerasan yang diterima TKI selama menjalankan tugasnya dan guna menyelamatkan TKI dari oknum yang ingin memperdagangkan mereka di luar negeri. Hukum sangat dibutuhkan guna melindungi setiap manusia yang merasa kurang dan belum siap secara politik, ekonomi dan sosial dalam mendapatkan keadilan bagi mereka (Hartono, 1991).

Berbagai cara telah dilakukan oleh pemerintah dalam melidungi rakyatnya di luar maupun dalam negeri. Berbagai peraturanpun telah di keluarkan untuk mengatasi masalah yang terjadi, namun dalam implementasinya masih banyak terdapat pelanggaranpelanggaran yang terjadi baik disengaja maupun tidak disengaja.

Perlindungan hukum terhadap hak dan kewajiban Tenaga Kerja Indonesia di luar negeri sudah termasuk kedalam hubungan kerja yang disepakati secara bersama. Asas ketepaduan; persesuaian hak. Demokrasi; kesamarataan bermasyarakat; kesetaraan; keadilan gender dan anti perdagangan manusia diatur dalam Pasal 2 UU No. 39 tahun 2004.

Bentuk perlindungan yang diberikan kepada TKI ada 3 terdiri dari; perlindungan sebelum pemberangkatan ialah suatu perlindungan dimana calon TKI akan diberikan iformasi mengenai syarat dan prosedur tahapan yang harus dilewati untuk menjadi TKI termasuk pengurusan dokumen, tahapan ini sangat penting untuk mencegah terjadinya TKI ilegal.

Kedua yaitu perlindungan selama berada pada wilayah kerja sesuai negara tujaan, dimana perlindungan ini mencakup mengenai hal-hal dorongan serta dukungan secara moral maupun fisik sesuai dengan ketentuan hukum wilayah tempat tujuan bekerja. Pemerintah melakukan pengawasan dan pembinaan mencegah terjadinya pelanggaran HAM yang dilakukan oleh majikan tempat TKI bekerja.

Ketiga ialah perlindungan yang diberikan kepada TKI setelah selesai masa kerja yang termasuk kedalamnya pemutusan hubungan kerja ataupun karena mengalami kecelakaan sampai dengan kegiatan deportasi pemerintah luar negeri tempat tujuan bekerja yang dikenakan pada TKI. Apabila seandainya dalam proses pemulangan TKI, terdapat TKI yang sudah meninggal dunia karena suatu alasan tertentu pihak pelaksana penempatan TKI wajib mengabarkan keluarga yang bersangkutan paling cepat satu hari setelah kematian TKI. Sesuai ketentuan yang ada pelaksana penempatan TKI juga harus memberikan biaya pemakaman yang bersangkutan, walaupun sudah meninggal penerimaan hak-hak TKI harus dipenuhi oleh jasa pelaksana pemberangkatan TKI.

Terdapat juga pelindungan hukum secara preventif dan juga kuratif untuk melindungi TKI di luar negeri. Perlindungan preventif untuk TKI merupakan suatu perlindungan dilakukan dengan cara edukatif yaitu pemberian informasi mengenai hak-hak dan kewaiban masing-masing pihak dalam melakukan suatu pekerjaan yang baik dan benar terutama dalam bidang pekerjaan asisten rumah tangga (ART) atau biasa disebut sektor infomal. Menegaskan apa saja kewajiban yang harus pekerja lakukan, hak apa yang pekerja dapatkan dan dalam betuk apa hak itu diterima oleh pekerja.

Apabila dalam suatu hubungan kerja terjadi pelanggaran terhadap kesepakatan dalam perjanjian kerja maka TKI juga mendapatkan perlindungan secara kuratif atau represif. Perlindungan ini diberikan apabila TKI mengalami suatu masalah hukum di negara tempanya bekerja. Sebagai upaya dalam perbaikan kondisi para korban. Dimungkinkan agar setiap korban mendapatkan keadilan dan perbaikan mental bagi yang mendapatkan kekerasan secara fisik guna melanjutkan kehidupannya dengan lebih baik. 


\section{Simpulan}

Berdasarkan uraian dan pembahasan yang telah dipaparkan di atas, dapat ditarik simpulan sebagai berikut:

Pengaturan Perjanjian Penempatan terhadap Tenaga Kerja Indonesia di Luar Negeri diatur dalam Pasal 31 Undang-Undang No. 39 Tahun 2004 tentang Penempatan dan Perlindungan Tenaga Kerja Indonesia Di Luar Negeri dengan adanya ketentuan penempatan yang dilakukan sebagimana termuat antara pelaksana penempatan TKI swasta dengan calon TKI yang berisi hak dan kewajiban tiaptiap aspek pada saat Penempatan Tenaga Kerja Indonesia ke negera sasaran sesuai pada peraturan perundang-undangan yang berlaku sudah menekan resiko terjadinya TKI ilegal dan perdagangan manusia (trafficking).

Perlindungan TKI Berdasarkan UndangUndang Nomor 39 Tahun 2004, perlindungan terhadap TKI sebagai pekerja ke luar negeri meliputi; Perlindungan TKI sebelum penempatan; Perlindungan TKI semasa penempatan; Perlindungan TKI setelah selesai bekerja dalam penempatan. Pemerintah juga memberikan perlindungan secara pereventif dan kuratif/represif untuk melindungi hak-hak TKI. Dalam hal ini tujuan dari perlindungan preventif yaitu untuk mencegah terjadinya kekerasan terhadap TKI. Sementara itu perlindungan secara kuratif atau represif yaitu perlindungan yang dilakukan apabila TKI bermasalah dan mengalami kekerasan dalam menjalankan tugasnya.

\section{DAFTAR PUSTAKA}

Fuqoha. (2018). Perlindungan Hukum Terhadap Kesempatan Kerja Bagi Masyarakat Lokal di Kota Cilegon. Wawasan Yuridika, 2(2). Retrieved from https:// core.ac.uk/download/ pdf/287307505.pdf

Hartono, S. (1991). Politik Hukum Menuju Satu Sistem Hukum Nasional. Bandung: Alumni.

Muin, F. (2015). Perlindungan Hukum Terhadap Tenaga Kerja Indonesia (Tinjauan Terhadap UU Nomor 39 Tahun 2004 Tentang Penempatan dan Perlindungan Tenaga Kerja Indonesia). Jurnal Cita Hukum, 3(1). Retrieved from http://journal.uinjkt.ac.id/ index.php/citahukum/article/view/1838

Raharjo, S. (2000). Ilmu Hukum. Bandung: PT. Citra Adityabakti.
Subekti. (1994). Pokok-Pokok hukum Perdata. Jakarta: Intermasa.

Supomo, I. (1999). Pengatar Hukum Perburuhan. Jakarta: Djambatan. 